\title{
Lung adenocarcinoma presenting as a solitary gingival metastasis: a case report
}

\author{
Armando Orlandi ${ }^{1 *}$, Michele Basso ${ }^{1}$, Mariantonietta Di Salvatore ${ }^{1}$, Francesco Federico ${ }^{2}$, Alessandra Cassano ${ }^{1}$ and \\ Carlo Barone
}

\begin{abstract}
Introduction: Gingival metastases are very rare and generally occur in disseminated tumors. We report a case of solitary gingival metastasis of lung cancer.

Case presentation: We report the case of a 74-year-old asymptomatic Caucasian woman affected by a rapidly growing, painless gingival swelling. Histopathologic examination of the excisional biopsy showed metastasis of poorly differentiated thyroid transcription factor 1-positive adenocarcinoma. A total-body computed tomographic scan revealed a tumor of the right lung lower lobe with ipsilateral, mediastinal lymph node swelling. Moreover, bone scintigraphy revealed no bone metastases. No other metastases were found, so we planned a multi-modal therapeutic approach with a curative intent. However, the tumor proved to be intrinsically resistant and highly aggressive.
\end{abstract}

Conclusion: The presentation of solitary gingival metastasis is exceptional. In view of its rapid clinical evolution, our case confirms that gingival metastasis is an important prognostic factor. This behavior raises the question whether the poor prognosis for patients with tumors with oral metastases depends on its diffuse spread or on its highly malignant nature.

\section{Introduction}

Oral metastatic tumors are rare, comprising approximately $1 \%$ of all oral tumors [1]. The jawbones are affected in $90 \%$ of the cases, whereas metastases to the soft tissues of the oral cavity occur very rarely and mostly involve the gingiva ( $54 \%$ of soft tissue metastases), followed by the alveolar mucosa or the tongue $[2,3]$. Metastases may reach the oral cavity hematogenously, mainly through inversion of the venous flow in the cervical Batson's plexus [4]. Alternatively, exfoliating cancer cells might be implanted in the oral mucosa by retrograde spreading along the respiratory tract or by cough [5]. The hyper-vascularization in inflamed periodontal tissues may be a causative factor [6]. In 30\% of cases, oral metastasis is the first manifestation of cancer, but it is often a sign of advanced disease with multi-metastatic involvement [7]. In fact, survival after recognition of gingival metastasis ranges from a few

\footnotetext{
* Correspondence: armando.orlandi@edu.rm.unicatt.it

'Division of Medical Oncology, Catholic University of Sacred Heart, Rome, Italy

Full list of author information is available at the end of the article
}

weeks to less than six months, with five-year survival lower than 5\% [7-10]. The poor prognosis related to this condition points out the importance of differentiating oral metastases from benign lesions, which often is achievable only by surgical excision. The case that we report here shows that a gingival metastasis may be the only presenting sign of lung adenocarcinoma, but it remains associated with a dismal outcome.

\section{Case presentation}

An apparently healthy, 74-year-old Caucasian woman who was a non-smoker and had no history of alcohol addiction presented with swelling of the vestibular gingival mucosa at the level of the lower right incisors (Figure 1). No other pathologic finding was noticed during the physical examination. She underwent an excisional biopsy of the lesion, and histopathologic immunohistochemistry showed a poorly differentiated adenocarcinoma expressing cytokeratin 7 and thyroid transcription factor 1, whereas cytokeratins 5, 6 and 20 were absent. The pattern suggested a metastasis of lung cancer (Figures 2, 3, 4). The total-body computed tomographic (CT) scan with contrast- 




Figure 1 Intra-oral view of the lesion developing in front of right jaw incisors.

enhancing medium revealed a $7.4 \mathrm{~cm}$-sized tumor of the lower lobe of the right lung with metastases to the ipsilateral mediastinal lymph nodes (cT3N2). No other metastases were detected, and her bone scan was also negative. An orthopantomogram of the dental arches excluded metastases to the jawbones (Figure 5). After multi-disciplinary clinical evaluation, sequential treatment was planned, including neoadjuvant chemotherapy (ChT) followed by concomitant chemoradiation and surgery. Platinum-based combination therapy was selected, but cisplatinum was excluded because the patient had lowgrade renal insufficiency with a serum creatinine level of $1.8 \mathrm{mg} / \mathrm{dL}$. Therefore, carboplatin area under the curve 6 on day one and gemcitabine $(1000 \mathrm{mg} / \mathrm{mq}$ on days one and eight) every three weeks were started. Two months later, after she had undergone three cycles of ChT, her CT scan showed clear expansion of the primary tumor with

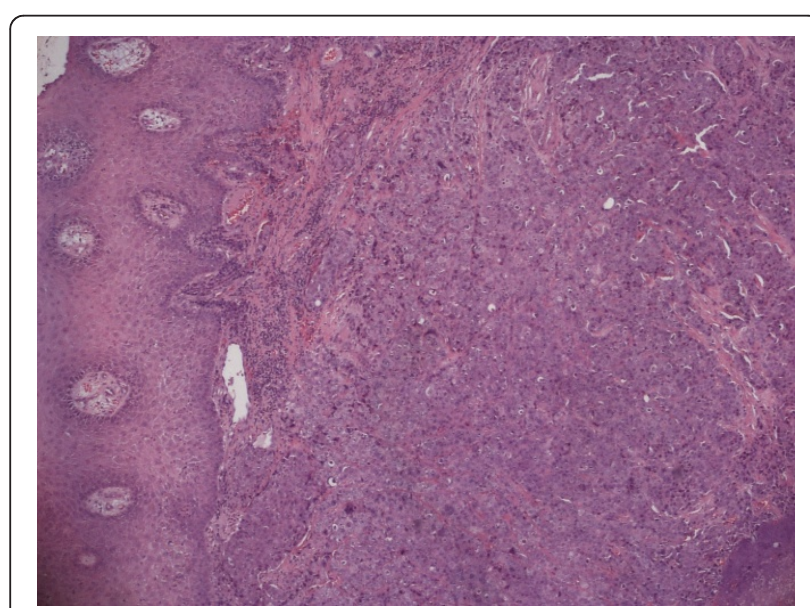

Figure 2 Histopathologic study showing proliferation of adenocarcinoma cells below the gingival epithelium (hematoxylin and eosin stain; original magnification, $\times 4$ ).

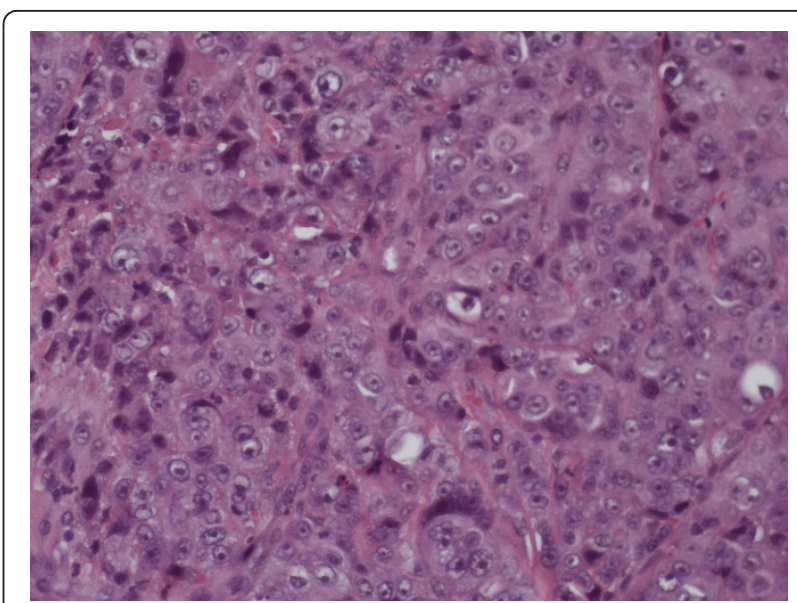

Figure 3 Histopathologic study showing proliferation of adenocarcinoma cells below the gingival epithelium

(hematoxylin and eosin stain; original magnification, $\times 20$ ).

diffuse infiltration of the right lung. A second-line treatment with docetaxel was attempted, but the tumor rapidly progressed and the patient died six weeks later as a result of respiratory failure.

\section{Discussion}

Metastatic tumors to the oral region are rare and mostly produced by breast, lung and kidney cancer, but other tumors may be also included [6]. Bone involvement is much more frequent than soft tissue involvement, and in the latter case lung cancer is the most common primary source. Hirshberg et al. [6] reviewed cases of oral metastases reported from 1916 to 1991 and found 157 cases of oral soft tissue metastases, 86 of which had gingival localization. The primary tumors were located in the lung (25.5\%), kidney (15.1\%), bone (10.4\%), breast $(9.3 \%)$ and liver (8.1\%). Yoshii et al. [11] estimated that



Figure 4 The tumor cells were immunoreactive for thyroid transcription factor 1 (original magnification, $\times 20$ ). 


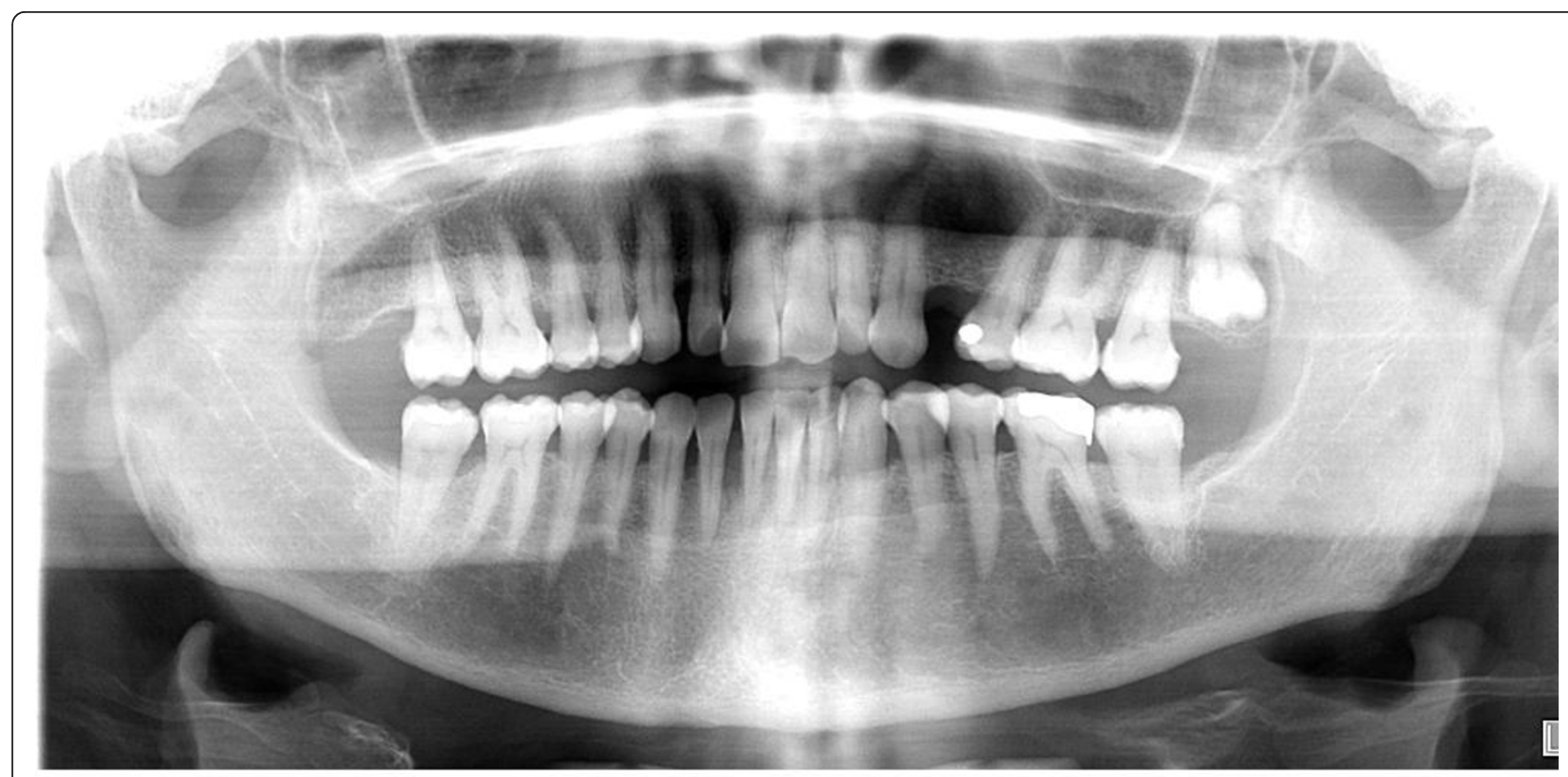

Figure 5 Panoramic radiography showing generalized alveolysis

the probability of lung cancer involving a diagnosis of gingival metastasis is about $10 \%$ to $20 \%$. Other authors have emphasized that the prognosis of patients with oral metastases is very poor, with a median survival of less than six months, mainly because of the fact that oral metastases are an expression of a multi-metastatic disease [12]. A recent review of 39 patients with oral metastases confirmed a median survival of 5.2 months without significant differences according to oral localization or to the site of the primary cancer [13]. In our patient, oral localization was the only metastasis detectable at presentation. To the best of our knowledge, no other similar cases have been described in the literature, and this calls attention to the importance of recognition of metastases to oral soft tissues. Most gingival lesions in patients with prior or current non-oral malignancies are not metastases [14]. Generally, gingival or oral mucosal metastases extend from mandibular or maxillary lesions and spread beyond the peri-osteum to cause visible gingival or oral mucosal masses [14]. Therefore, gingival metastases are polypoid or exophytic and highly vascularized, and bleeding is very common [8-10,15-17]. The same characteristics are also displayed by a number of benign lesions, such as pyogenic granuloma (or vascular epulis), peripheral giant cell granuloma (giant cell epulis) or fibrous epulis [18]. From a clinical point of view, the aspects suggestive of malignancy are only the rapid growth and the propensity for either necrosis or hemorrhage. In these cases, the possibility of metastasis should be kept in mind, and biopsy is mandatory.
In our patient, no other metastases were found; therefore, we planned a multi-modal therapeutic approach with a curative intent. However, the tumor proved intrinsically resistant and highly aggressive. This behavior raises the question whether the poor prognosis of patients with tumors with oral metastases depends on their diffuse spread or on their highly malignant nature. Early detection might be important in metastases from chemosensitive tumors, whereas chemoresistant tumors, such as lung cancer, the present therapeutic strategies are largely ineffective, and oral metastases should be considered as only a negative prognostic factor.

\section{Conclusion}

In view of the rapid clinical evolution, in spite of the fact that this is a single case report and no clear diagnostic recommendations can be made on the basis of a single report, the present case of our patient supports the fact that gingival metastasis is an important prognostic factor. Thus, given the malignant potential and the diagnostic value of a gingival metastasis, it is essential to carry out the excision of any presumed benign tumor within healthy boundaries and to ask for a systematic histopathological examination.

\section{Consent}

Written informed consent was obtained from the patient for publication of this case report and any accompanying images. A copy of the written consent is available for review by the Editor-in-Chief of this journal. 


\section{Author details}

'Division of Medical Oncology, Catholic University of Sacred Heart, Rome, Italy. ${ }^{2}$ Department of Pathology, Catholic University of Sacred Heart, Rome, Italy.

\section{Authors' contributions}

OA collected the data and was involved in drafting the manuscript. DM and FF participated in the acquisition of data. BM, CA and BC were involved in drafting the manuscript or revising it for important intellectual content. All authors read and approved the final manuscript.

\section{Competing interests}

The authors declare that they have no competing interests.

Received: 23 June 2010 Accepted: 25 May 2011 Published: 25 May 2011

\section{References}

1. Meyer I, Shklar G: Malignant tumors metastatic to mouth and jaws. Oral Surg Oral Med Oral Pathol 1965, 20:350-362.

2. Sánchez Aniceto G, García Peñín A, de la Mata Pages R, Montalvo Moreno Jj: Tumors metastatic to the mandible: analysis of nine cases and review of the literature. J Oral Maxillofac Surg 1990, 48:246-251.

3. Hirshberg A, Leibovich P, Buchner A: Metastases to the oral mucosa: analysis of 157 cases. J Oral Pathol Med 1993, 22:385-390.

4. Batson OV: The function of the vertebral veins and their role in the spread of metastases. Ann Surg 1940, 112:138-149.

5. Chossegros C, Blanc JL, Cheynet F, Bataille JF, Tessier H: [Metastatic localization in the buccal cavity: case report and literature review] [in French]. Rev Stomatol Chir Maxillofac 1991, 92:160-164.

6. Lamster IB, Karabin SD: Periodontal disease activity. Curr Opin Dent 1992, 2:39-52.

7. Hirshberg A, Leibovitch P, Buchner A: Metastatic tumours to the jaw bones: analysis of 390 cases. J Oral Pathol 1994, 23:337-341.

8. McDaniel RK, Luna MA, Stimson PG: Metastatic tumors in the jaws. Oral Surg Oral Med Oral Pathol 1971, 31:380-386.

9. Morishita M, Fukud J: Hepatocellular carcinoma metastatic to the maxillary incisal gingiva. J Oral Maxillofac Surg 1984, 42:812-815.

10. Maiorano E, Piatelli A, Favia G: Hepatocellular carcinoma metastatic to the oral mucosa: report of a case with multiple gingival localizations. J Periodontol 2000, 71:641-645.

11. Yoshii T, Muraoka S, Sano N, Furudoi S, Takahide K: Large cell carcinoma of the lung metastatic to the mandibular gingiva. J Periodontol 2002, 73:571-574.

12. Van der Waal RI, Buter J, van der Waal I: Oral metastases: report of 24 cases. Br J Oral Maxillofac Surg 2003, 41:3-6.

13. Seoane J, Van der Waal I, Van der Waal Rl, Cameselle-Teijeiro J, Antón I, Tardio A, Alcázar-Otero JJ, Varela-Centelles P, Diz P: Metastatic tumours to the oral cavity: a survival study with a special focus on gingival metastases. J Clin Periodontol 2009, 36:488-492.

14. Kadokura M, Yamamoto S, Kataoka D, Nonaka M, Tanio N, Kunimura T, Kushima M, Kushihashi T, Kawada T, Takaba T: Pulmonary adenocarcinoma metastatic to the gingiva. Int I Clin Oncol 1999, 4:253-255.

15. Wegwood D, Rusen D, Balks $S$ : Gingival metastasis from primary hepatocellular carcinoma: report of a case. Oral Surg Oral Med Oral Pathol 1979, 47:263-266.

16. Nishimura Y, Yakata H, Kawasaki T, Nakajima T: Metastatic tumours of the mouth and jaws: a review of the Japanese literature. J Oral Maxillofac Surg 1982, 10:253-258.

17. Kanazawa $\mathrm{H}$, Sato K: Gingival metastasis from primary hepatocellular carcinoma: report of a case and review of literature. J Oral Maxillofac Surg 1989, 47:987-990.

18. Hirshberg A, Buchner A: Metastatic tumours in the oral region: an overview. Eur J Cancer B Oral Oncol 1995, 31B:355-360.

doi:10.1186/1752-1947-5-202

Cite this article as: Orlandi et al.: Lung adenocarcinoma presenting as a solitary gingival metastasis: a case report. Journal of Medical Case Reports 2011 5:202.

\section{Submit your next manuscript to BioMed Central and take full advantage of:}

- Convenient online submission

- Thorough peer review

- No space constraints or color figure charges

- Immediate publication on acceptance

- Inclusion in PubMed, CAS, Scopus and Google Scholar

- Research which is freely available for redistribution

Submit your manuscript at www.biomedcentral.com/submit
Ciomed Central 